\title{
Development of environmentally safe acid- resistant ceramics using heavy metals containing waste
}

\author{
Irina Vitkalova ${ }^{1}$, Anastasiya Torlova ${ }^{1}$, Evgeniy Pikalov $^{1, *}$, and Oleg Selivanov ${ }^{1}$ \\ ${ }^{1}$ Vladimir State University named after A.G. and N.G. Stoletovs, 600000 Vladimir, Russia
}

\begin{abstract}
The paper presents research results concerning charge composition development to produce environmentally safe acid-resistant ceramics on the basis of low-plastic clay of the Vladimir region possessing self-glazing effect. 5 wt. \% boric acid, 5 wt. \% lanthanum oxide and up to 5 wt. \% electroplating sludge have been introduced into the charge composition as functional additives. Boric acid serves as a flux and a source acid-resistant and heat-resistant vitreous phase based on borosilicates, but compositions contained in the electroplating sludge are decomposed in the process of ceramics firing causing the formation of calcium oxide and heavy metal oxides, which additionally increase material acid-resistance and heatresistance like lanthanum oxide. To receive the developed material, semidry pressing technology has been applied under the charge forming moisture of $8 \mathrm{wt} . \%$, specific pressure of $15 \mathrm{MPa}$ and one-stage firing at max temperature of $1050{ }^{\circ} \mathrm{C}$. The research presents the testing results of ceramics principal operating properties and environmental safety. The developed material can be used in clinker and acid-resistant bricks and tiles production for masonry and tiling in aggressive environment like buildings foundations and bases, premises with high moisture, as well as in sewerage systems, chimneys and ventilation ducts.
\end{abstract}

\section{Introduction}

Heavy metals are known to refer to the metals of 50 AWU. They differ in their high density and good electric conductivity. They include refractory and low-melting, hard and plastic metals.

Heavy metals and they compositions are widely applied in metallurgy, machine-building, chemical and electrochemical industries, in textile, glass, ceramics, polymer production and pharmaceutics. Heavy metals and their compounds are applied in construction and in electrotechnical units production. They are used as functional additives like fillers, stabilizers etc.

Multi-tonnage production of the enumerated industries causes huge amount of gaseous emissions, waste water discharge and solid waste containing heavy metals and their compounds. Environment pollution by this waste is very dangerous as heavy metals are characterized by their toxicity and low maximum permissible discharge. Heavy metals

\footnotetext{
*Corresponding author: evgeniy-pikalov@mail.ru
} 
hazard enhances their ability to be accumulated in soil and live organisms, moreover many of them can form stable complex organic compounds possessing good solubility in aqueous media, thus facilitating their migration causing contamination of new areas and water sources.

The most environmentally hazardous is galvanic sludge formed during chemical treatment of waste water, rinsing solutions and spent electrolytes used in electroplating processes. On the one hand, electroplating sludge hazard depends on high concentration of heavy metals and their compounds, on the other hand, nowadays there are no universal waste water treatment technologies for electroplating effluents processing. Heavy metals and their compounds leaching from galvanic sludge is a hard and time-consuming process, but their application as additives in the production of concrete, ceramics and other silicate materials does not allow to dispose of large quantities galvanic sludge.

In this connection the disposal technology development for electroplating sludge is a vital issue for scientific research, especially in the regions where electroplating production is widely spread. The interest in this respect causes the ability not just to dispose galvanic sludge, containing heavy metals, but to use it as a functional additive altering the properties of silicate materials.

The report authors previously conducted research for the developing the charge compositions on the basis of low-plasticity clay from the Vladimir region, using galvanic sludge for producing environmentally safe construction ceramics [1-4], thus allowing to expand the regional raw material base and to solve the toxic waste disposal problem. In the current research ceramics ecologic safety, endurance and frost resistance were provided by the introduction of boric acid together with the galvanic sludge into the charge, which forms an amorphous vitreous phase, filling the pores and voids in the material during its firing. Vitreous phase prevents heavy metals migration when ceramics is contacting water and simultaneously binds the particles of the material [2]. To increase ceramics endurance and frost-resistance the amount of the formed vitreous phase was increased and self-glazing effect on ceramics surface due to additional introduction of glass crash [3] or titanium dioxide [4] at firing temperature of $1050{ }^{\circ} \mathrm{C}$ enhanced. Herewith titanium dioxide allows achieving total environmental safety of the produced ceramics.

The research objectives were to preserve ecologic safety of the produced ceramics and to improve its surface self-glazing effect simultaneously with the additional increase of its endurance and frost-resistance. Besides it was important to achieve high acid-resistance and heat-resistance of the produced material. Solving these issues will permit to use the ceramics, produced on the basis of the developed composition, for the production of acid-resistant products.

\section{Materials and Methods}

The basic charge component during the research was the clay from the Suvorotskoye field in the Vladimir region of the following composition (wt. \%): $\mathrm{SiO}_{2}=67,5 ; \mathrm{Al}_{2} \mathrm{O}_{3}=10,75 ; \mathrm{Fe}_{2} \mathrm{O}_{3}$ $=5,85 ; \mathrm{CaO}=2,8 ; \mathrm{MgO}=1,7 ; \mathrm{K}_{2} \mathrm{O}=2,4 ; \mathrm{Na}_{2} \mathrm{O}=0,7$. The presence of aluminum, calcium and magnesium oxides, as well as plasticity index $-5002 \mathrm{C} 2$, defined by the standard method, indicates that this clay belongs to the low-plasticity group according to GOST 9169-75 [4].

Electroplating sludge from PLC "Zavod "Avtopribor" (Vladimir city), the residue of chemical waste water treatment of the industrial electroplating process with moisture of 60$70 \%$, was introduced into the developed charge. The sludge contains the following elements (wt. \%): $\mathrm{Zn}(\mathrm{OH})_{2} \approx 11,3 \% ; \mathrm{SiO}_{2} \approx 7,08 \% ; \mathrm{Ca}(\mathrm{OH})_{2} \approx 16,52 \% ; \mathrm{Cr}(\mathrm{OH})_{3} \approx 9,31 \% ;\left(\mathrm{Fe}^{2+}\right) \mathrm{Cr}_{2} \mathrm{~S}_{4}$ $\approx 4,17 \% ; \mathrm{CaCO}_{3} \approx 40,25 \% ; \mathrm{CaO} \approx 3,45 \% ; \mathrm{ZnO} \approx 2,41 \% ; \mathrm{Cu}(\mathrm{OH})_{2} \approx 2,38 \% ; \mathrm{Ni}(\mathrm{OH})_{2} \approx$ $2,62 \% ; \mathrm{Mn}(\mathrm{OH})_{2} \approx 0,64 \% ; \mathrm{Pb}(\mathrm{OH})_{2} \approx 0,14 \%$. The presence of considerably big amount of zinc, chromium, nickel and copper compounds as hydroxides prove the sludge toxicity [3]. 
To form vitreous phase and ceramics surface self-glazing, boric acid brand B 2-nd grade (GOST 18704-78) and lanthanum oxide (TU 48-4-523-89) were introduced into the charge.

To produce ceramics samples, the clay and electroplating sludge were pre-ground and dried to a constant mass, while for further experiments particle size fraction of less than 0.63 $\mathrm{mm}$ was selected. Afterwards all charge components were mixed to obtain a molding mass with 8 wt. \% moisture, from which the samples were produced under specific pressing pressure of $15 \mathrm{MPa}$ and a firing temperature of $1050^{\circ} \mathrm{C}$. Several batches by 3 samples each were produced using the researched composition.

To assess the impact of additives in the charge samples in compliance with standard methods principle properties have been determined: compressive strength $\left(\sigma_{\mathrm{cs}}, \mathrm{MPa}\right)$, bending strength $\left(\sigma_{\mathrm{bs}}, \mathrm{MPa}\right)$, water absorption $(\mathrm{W}, \%)$, frost-resistance $(\mathrm{F}$, cycles), acidresistance (AR, \%) and thermo-stability (TS $\left(1000^{\circ} \mathrm{C}\right.$ - water), thermo-shifts).

As electroplating sludge refers to 2-3 hazard class [2], and boric acid to the 3-d class the research has been carried out for the assessment of environmental safety of the produced ceramics according to determination method of Daphnia magna Straus mortality under the impact of toxic substances in the daily aqueous extract from the researched samples [5].

\section{Results}

The first research stage was devoted to the determining of pressure strength and water absorption dependence as basic physical-mechanical material properties on galvanic sludge and lanthanum oxide content in the charge with additional introduction of boric acid in an amount of $5 \mathrm{wt}$. \%. The choice of boric acid amount was proved by the previous experiments which demonstrated that big amount of acid does not considerably change the produced ceramics characteristics and the excess of the vitreous phase causes deformation, but small amount leads to ceramics lower pressure strength and higher water absorption [4]. Besides it is necessary to consider boric acid toxicity, which is revealed during its introduction into the charge in the amount exceeding 5 wt. $\%[3,4]$.

Experimental research results are shown in Fig.1. The obtained data proves that an increase in the galvanic sludge content in the charge decreases its compressive strength and increases water absorption. It depends on the heavy metals hydroxides and calcium carbonate presence in the sludge which decompose in the process of ceramics firing releasing water vapor and carbon dioxide thus enhancing material porosity and reducing its strength. The increase of lanthanum oxide content in the charge leads to the inverse dependences of electroplating sludge impact which occurs due to lanthanum oxide forming a vitreous phase which amount increases when boric acid is introduced.

The dependences alignment of the compressive strength on the injected additives amount with the galvanic sludge introduction up to $5 \mathrm{wt}$. \% and on lanthanum oxide from 3 to $5 \mathrm{wt}$. $\%$ is connected with heavy metal oxides, formed during hydroxides decomposition, which also increase the amount of the formed vitreous phase. However electroplating sludge introduction over $5 \mathrm{wt}$ \% in the material during its firing causes high internal pressure thus leading to the cracking in material volume and products deformation. Practically linear dependence of water absorption and galvanic sludge amount in the charge at the introduction of $5 \mathrm{wt}$ \% lanthanum oxide is connected with the fact that in this case almost all open pores transform into the closed ones. 


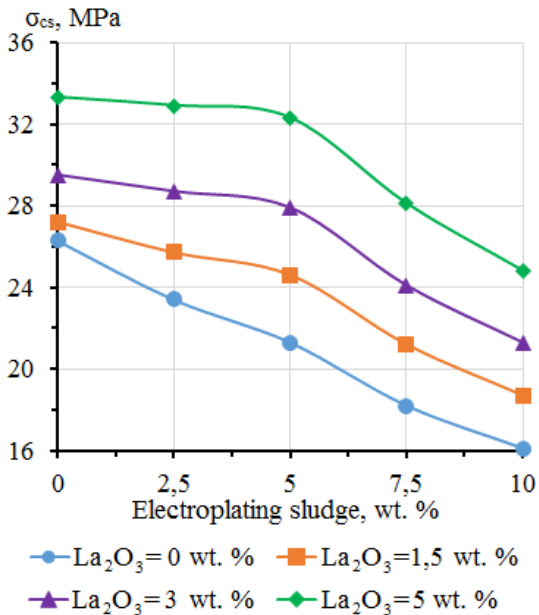

a)

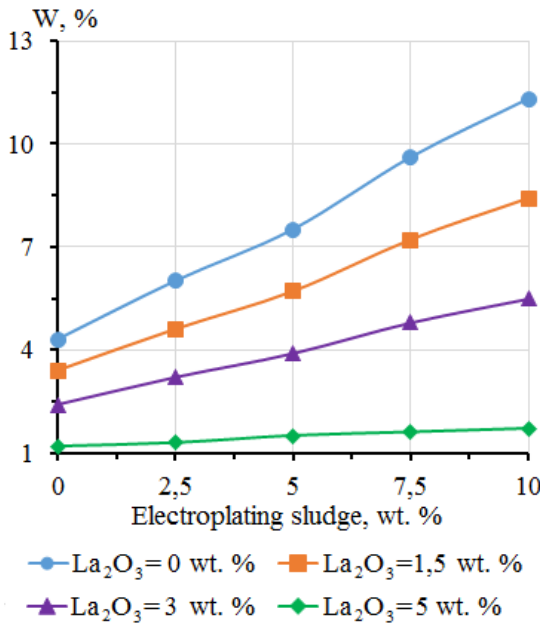

b)

Fig. 1. Dependence of pressure strength (a) and water absorrption (b) on electroplating sludge and lanthanum oxide amount in the researche ceramics.

It should be mentioned that the introduction of over $5 \mathrm{wt} . \%$ of lanthanum oxide causes insignificant increase of ceramics strength and water absorption in comparison with the introduction of $5 \mathrm{wt.} \%$ of lanthanum oxide. Moreover, Introduction of over $5 \mathrm{wt} . \%$ of lanthanum oxide leads to the excess amount of vitreous phase and samples deformation.

The second research stage revealed dependences of acid and thermal resistance of the researched compositions on the introduced amount of galvanic sludge and lanthanum oxide, presented in Fig.2.

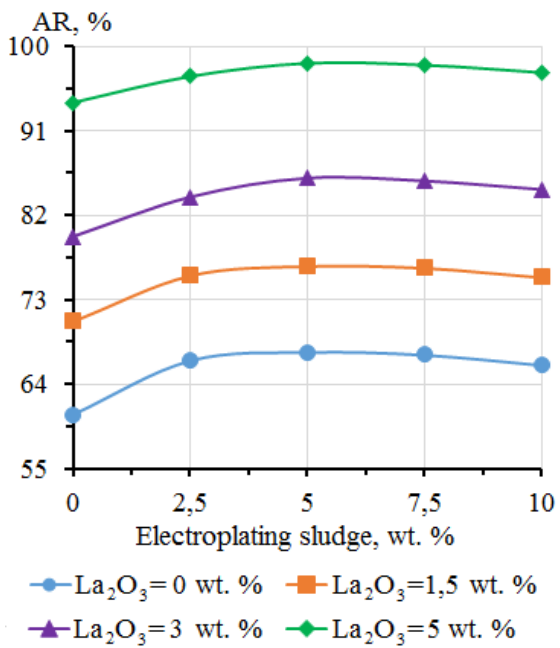

a)

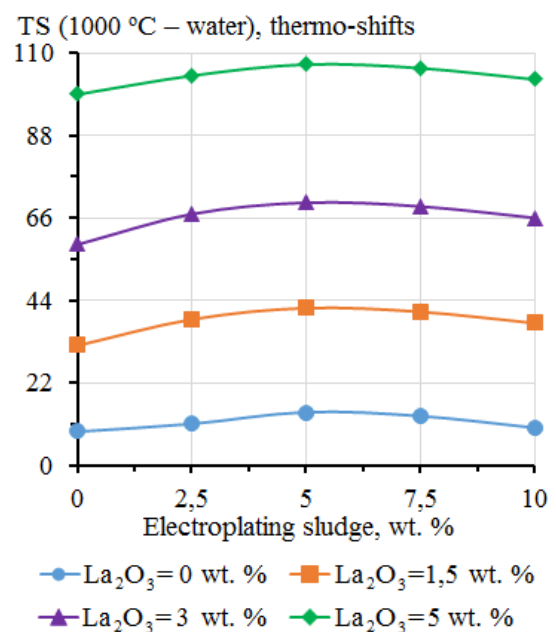

b)

Fig. 2. Dependence of acid resistance (a) and thermal resistance (b) of the researched ceramics og electroplating sludge and lanthanum oxide content. 
The received data prove that lanthanum oxide enhances the considered properties, but galvanic sludge dependence is characterized by the parabolic nature. The ceramics acid and thermal resistance increase alongside galvanic sludge amount in the charge which is connected with the highest content of zinc and chromium compounds in the sludge. In their turn zinc and chromium oxides, formed from their compounds at firing enhance the described characteristics $[6,7]$. Calcium oxide, introduced into the developed material through galvanic sludge and clay, additionally increase chemical resistance [6].

Insignificant decrease of acid-resistance alongside the increase of electroplating sludge amount in the charge depends on the ability of the addidtive to enhance porosity and consequently it facilitates the penetration of aggressive media into the material depth and increases contacting surface area. The reason for the insignificant decrease of thermalstability is similar, as porosity enables water to penetrate into the samples during the experiments.

It should also be highlighted that silicon and aluminum oxides present in the used clay, as well as boron oxide, formed from boric acid during firing and interacting with silicon oxide to obtain borosilicates, increase both of the considered properties. Boron oxide can decrease chemical stability in case its content exceeds $13 \%$ [8], however its amount in the developed composition is much lower. According to the received dependences, shown in Fig 1 and 2, the following research was based on the compositions, containing $5 \mathrm{wt} . \%$ of lanthanum oxide and $5 \mathrm{wt} . \%$ of boric acid for introducing up to $10 \mathrm{wt} . \%$ of electroplating sludge. The results of ceramics properties determining and its environmental safety of the researches samples are presented in the Table and Fig.3.

Table. Acid-resistant ceramics.

\begin{tabular}{|l|c|c|c|c|c|}
\hline \multirow{2}{*}{ Properties } & \multicolumn{5}{|c|}{ Electroplating sludge, wt. \% } \\
\cline { 2 - 6 } & 0 & 2,5 & 5,0 & 7,5 & 10,0 \\
\hline Compressive strength, MPa & 33,3 & 32,9 & 32,3 & 28,1 & 24,8 \\
\hline Bending pressure, MPa & 4,9 & 4,5 & 4,6 & 3,9 & 3,5 \\
\hline Water absorption, \% & 1,2 & 1,3 & 1,5 & 1,6 & 1,7 \\
\hline Frost resistance, cycles & 50 & 60 & 77 & 76 & 75 \\
\hline Acid resistance, \% & 96 & 97,6 & 98,2 & 98 & 97,2 \\
\hline $\begin{array}{l}\text { Thermal resistance, }\left(1000^{\circ} \mathrm{C}-\right. \\
\text { water), thermal shifts }\end{array}$ & 99 & 104 & 107 & 106 & 103 \\
\hline
\end{tabular}

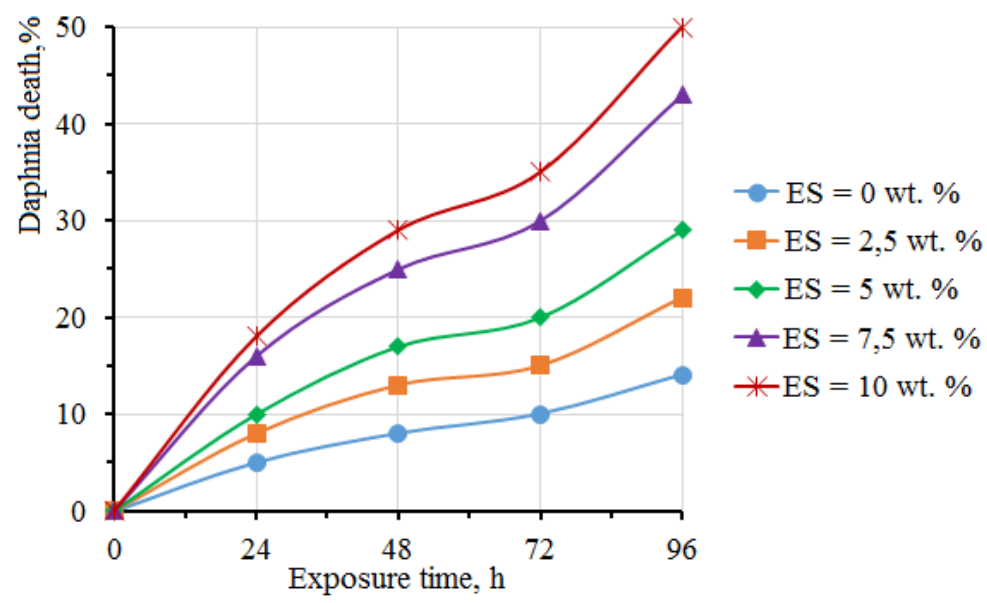

Fig. 3. Daphnia death dynamics in water extract at various amount of electroplating sludge (ES) in the charge. 
As the received data proves, the developed staff permits to produce ecologically safe acidresistant ceramics using galvanic sludge up to $10 \mathrm{wt} . \%$, though when galvanic sludge reaches 7,5 to 10 wt.\% strength is decreasing but water absorption if rising. Daphnia death is approaching maximum permissible $50 \%$.

\section{Conclusions}

The research results demonstrate that low plasticity clay after introducing $5 \mathrm{wt} . \%$ of boric acid, $5 \mathrm{wt} . \%$ of lanthanum oxide and up to $5 \mathrm{wt} . \%$ of galvanic sludge can be used for producing environmentally safe acid-resistant ceramic material. The peculiarity of the developed charge composition is its self-glasing effect received during joint introduction of the additives. This effect is acheived due to boric acid serving as a flux and a glass-forming additive, while lanthanum oxide together with calcium and heavy metals oxides present in galvanic sludge as compounds serve as functional additives enhancing acid and thermal resistance. Boric acid is also a source of boron oxide which additionally increases acid and thermal resistance together with alminium and silicon oxides present in the clay.

The developed material, produced in the cource of research, can be applied in ceramic produts manufacturing principally for clinker and acid-resistant bricks, acid-resistant tiles for masonry and tiling in the aggressive media, in particular for the foundations and walls bases, basements, retaining walls construction, columns, parapets, outer walls of the premises with wet environment, for sewage systems, chimneys and ventilation ducts.

\section{References}

1. M.A. Sukharnikova, E.S. Pikalov, O.G. Selivanov, É.P. Sysoev, V.Y. Chukhlanov, Glass and Ceramics 73 (3-4), 100-102 (2016)

2. E.S. Pikalov, O.G. Selivanov, V.Y. Chukhlanov, N.V. Chukhlanova, Ecology and industry in Russia 6, 24-29 (2017)

3. I. Vitkalova, A. Torlova, E. Pikalov, O.Selivanov, Industrial waste utilization in the panels production for high buildings facade and socle facing, E3S Web of Conferences 33, 02062 (2018) doi.org/10.1051/e3sconf/20183302062

4. A.A. Vorob'eva, V.N. Shakhova, E.S. Pikalov, O.G. Selivanov, É.P Sysoev, V.Y. Chukhlanov, Glass and Ceramics 75 (1-2), 51-54 (2018)

5. Toxicity determination method of water and water extractions from soil, waste water sediments, waste by Daphnia death and fertility change. Federal registry FR.ФP.1.39.2007.03222. Moskow: Aquaros, p.41 (2007)

6. V.P. Khramkov, E.A. Chugunov, Materials for glass and glass works production and processing (Moscow: High school, 1987)

7. I.V. Riskin, Belenky E.F., Pigments chemistry and technology (Leningrad, Goskhimizdat, 1960)

8. K.A. Polyakov, F.B. Slomyanskaya, K.K. Polyakova Corrosion and chemically resistant materials (Leningrad, Goskhimizdat, 1953) 